\title{
Positive association between rat abundance and breeding success of the Critically Endangered Mariana Crow Corvus kubaryi
}

\author{
ARJUN AMAR and JACOB A. ESSELSTYN
}

\section{Summary}

Diagnosing the causes of population declines of highly endangered species is vital to ensure that appropriate conservation measures are undertaken. Although experiments can provide critical information on potential causes, these can be time consuming and costly, and so it is important to determine the most plausible hypothesis for such tests. The last wild population of the Critically Endangered Mariana Crow Corvus kubaryi has been declining rapidly on Rota in the Mariana Islands. Because nest predation by introduced rats Rattus spp. has been implicated in the declines of other Pacific island birds, we tested for a correlation between breeding success of Mariana Crows and abundance of rats $R$. diardii surrounding their nest sites. If rats are a contributing factor in this species's decline, we predicted that breeding success would be lower in areas where rats were more abundant. In complete contrast to this prediction, we found that breeding success was significantly higher where rats were most abundant, suggesting that rats are unlikely to be a major driving force behind the decline in this species. The positive association between crow breeding success and rat abundance suggests these species may be responding to similar habitat needs or a shared predator. This study illustrates the importance of gathering sufficient knowledge on the ecology of a species prior to undertaking costly, logistically difficult and time consuming experiments.

\section{Introduction}

Identifying the causes of population declines is necessary if appropriate conservation actions are to be implemented. Experimental manipulation of the putative agent is the clearest way of establishing cause. However, because such experiments require sufficient replicates to provide statistical power, field experiments that aim to identify limiting factors on wild populations are expensive, time consuming and sometimes logistically impossible and are consequently relatively rare (Newton 1998, Caughley 1994, Amar and Redpath 2002). Adaptive management approaches may address some, but not all, of these limitations (Parkes et al. 2006). Therefore, before undertaking any such experiments it is prudent to conduct correlative analyses to establish whether the factor(s) under consideration is potentially responsible. Building supportive evidence prior to any experimental manipulation or adaptive management potentially saves limited financial resources and valuable time (Caughley 1994).

The Pacific island of Rota, one of the Mariana Islands, is an important Endemic Bird Area (Birdlife International 2003). It has a unique avifaunal assemblage, which includes the Mariana Crow Corvus kubaryi, a "Critically Endangered" species (BirdLife International 2008). Alarmingly, numbers of Mariana Crows continue to decline rapidly on Rota, with the most recent estimates suggesting a 94\% decline between 1982 and 2004 (Plentovich et al. 2005, Amar et al. 2008). 
Recent estimates suggest that only 85 pairs remain on Rota (Amar et al. 2008), making it one of the rarest bird species in the world (Birdlife International 2008). The Mariana Crow was also native to the neighbouring island of Guam, but the population there became extirpated in 2011 because of predation by the introduced brown tree snake Boiga irregularis and the failure of a small translocation and captive rearing programme using eggs and birds from Rota to rescue the population (Aguon et al. 2002, Wiles et al. 2003, USFWS 2005, J. Quitugua pers. comm.). To ensure the continued survival of the Rota population, there is a pressing need to gain an improved understanding of the species's ecology, including identifying the factors that are currently limiting its breeding success.

One hypothesis proposed for the Rota population decline is predation of nest contents by introduced rats Rattus diardii (Duckworth et al. 1997, USFWS 2005). There is abundant evidence that the introduction of non-native rats (Rattus spp.) on small, isolated islands has a negative impact on native avian populations (Atkinson 1985, Jones et al. 2007, Towns et al. 2006). Bird species on many isolated Pacific islands, including Rota, have evolved in the absence of such predators and rat introductions can have dramatic consequences for the survival and breeding success of native bird populations. Several such cases have resulted in extinction (Bell 1978, Thibault et al. 2002, Ortiz-Catedral et al. 2009).

On Rota, however, there is no direct evidence to implicate rats in the decline of Mariana Crows and no confirmed instance of rat predation on their nests. There is also currently no federally approved rodenticide licensed for broad-scale rat control on Rota (Fred Amidon pers comm.). Therefore, before undertaking a logistically and financially difficult rat removal experiment, we considered it prudent to seek evidence in support of this hypothesis. To obtain supporting evidence, we measured the abundance of rats around crow nests with known histories. If we assume that rat predation rates are highest where rat abundance is highest (Igual et al. 2006) and that rat predation is a major limiting factor, then we predict that nests in areas of high rat abundance should fail more frequently than nests in areas with lower rat abundance.

\section{Methods}

\section{Study area}

Rota $\left(14^{\circ} 10^{\prime} \mathrm{N}, 145^{\circ} 12^{\prime} \mathrm{E}\right)$ is part of the Mariana Archipelago, a chain of 15 islands located approximately $1,500 \mathrm{~km}$ east of the Philippines. Rota is a rugged island $\left(85 \mathrm{~km}^{2}, 491 \mathrm{~m}\right.$ max. elev.) comprised primarily of raised limestone. The climate is tropical, with an average annual temperature of $26^{\circ} \mathrm{C}$ and annual precipitation of 2,000-2,600 mm (Kendrick 1997). The most recent estimates of forest cover, from the late 1970 and early 1980s (Falanruw 1989), suggest that the island has approximately $80 \%$ forest cover. Mariana Crow nests are typically situated in forests dominated by native tree species (Ha et al. 2011).

\section{Nest searching and monitoring}

Based on previously known territories (Morton et al. 1999), we identified and monitored occupied territories from July 2003 until May 2004. The core areas of each monitored pair's territory were surveyed every $2-3$ weeks. Monitoring involved entering the core territorial areas and listening for calling crows. We then attempted to locate calling crows and assess their status (i.e. foraging as a pair, nest building, etc.). Mariana Crows become particularly aggressive immediately prior to and during breeding, therefore this was used as a key indicator as to the current breeding state of the pair. Figure 1 shows the locations of nests used in this study.

Once a nest was located within a territory, the current stage of the nest was recorded, i.e. nest building, incubating, or chick rearing. This was assessed by examining the state of the nest structure and observing adult crow behaviour. When a nest was believed to have either eggs or chicks, we used a 10-m telescopic mirror pole to view the nest contents and determine clutch size and 


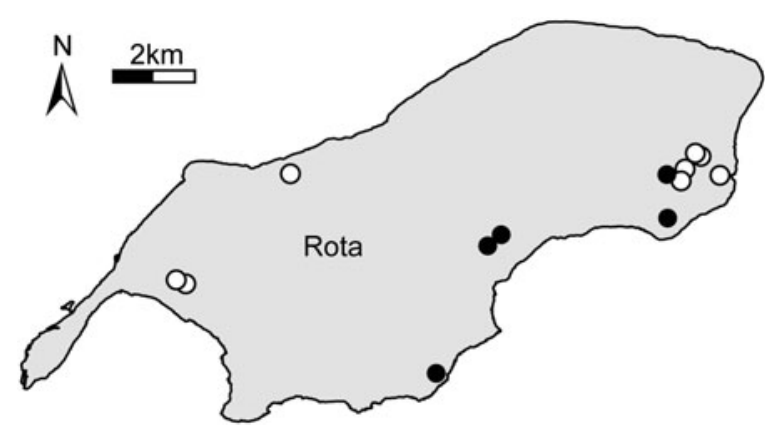

Figure 1. Map of Rota showing the locations of the successful (solid circles) and failed nests (open circles).

developmental stage. Nest sites were then visited (where possible) approximately every 7-10 days until fledging, near fledging, or failure. Our aim was to find as many nests as possible to allow comparisons of rat abundance between failed and successful nests, rather than to estimate hatching or breeding success rates of the population as a whole (Mayfield 1975).

\section{Rat surveys}

We estimated relative rat abundance around nest sites through kill trapping, carried out on average $29 \pm 6$ days ( \pm I SE; range o-6I days) after failure or fledging. There was no significant difference in the time lag of rat sampling between failed and successful nests $\left(\chi^{2}{ }_{1}=0.25, P=0.62\right)$ and all trapping occurred between December 2003 and June 2004. This period represents the dry season on Rota where rainfall varies little from month to month, hence there was unlikely to be large temporal fluctuations in resources and consequently rat abundance over this period.

We set a $5 \times 5$ grid of Victor rat traps spaced at $25 \mathrm{~m}$ intervals (thus sampling occurred over a $100 \mathrm{~m} \times 100 \mathrm{~m}$ area), with the nest tree as the central point of the grid. No trap was placed at this central point, hence each grid included 24 traps. This grid size was considered adequate to survey rats in the immediate area, since previous research on the neighbouring island of Guam suggested that Rattus spp. have relatively small ranges in this region, with average distance between re-traps being only around 27 and $37 \mathrm{~m}$ for male and female rats, respectively (Baker 1946). To reduce the risk of capturing crows, traps were fixed inside hollow tubes of wire mesh. Tubes (40 $\mathrm{cm}$ long and $15 \mathrm{~cm}$ diameter) were attached with tie wire along horizontal or near horizontal branches as close as possible to the desired point within the trapping grid. Traps were placed in elevated $(1-2 \mathrm{~m})$ positions to avoid capturing crabs, and also because rats were known to be arboreal and to be captured at a higher rate by traps placed on tree branches than on the ground (Morton et al. 1999). Traps were baited with coconut and peanut butter and were pre-baited for one day prior to trapping. Traps were then set for a total of three nights. We checked and reset traps each morning. After the first night, any missing bait was replaced, and after the second night all bait was replaced with fresh bait regardless of whether it was missing or not. Thus, there was the potential for a maximum of 72 trap nights over the course of the trapping period ( 3 nights $x$ 24 traps). Trap nights were calculated from the total potential trap nights per night $(n=24)$, minus the number of snapped traps and the number of other captures (exclusively either hermit crabs Coenobita spp. or coconut crabs Birgus latro) divided by two, thereby assuming tripped traps were available to catch rats for half the night (Nelson and Clark 1973). Our rat abundance index was then calculated as the average number of rats caught/trap night over these three sessions. A subset of rats captured were prepared as voucher specimens and deposited in the Field Museum of Natural History, Chicago. Although uncertainty exists as to the exact species of rat on Rota, recent genetic work (Wiewel et al. 2009) suggests that the commonest species present on 
Rota is Rattus diardii (Robins et al. 2007) which belongs to the $R$. rattus complex and is treated by some authorities as synonymous with $R$. tanezumi (Carleton and Musser 2005). In keeping with Wiewel et al. (2009) we tentatively refer to the rats caught in this study as $R$. diardii.

\section{Statistical analyses}

Analyses were conducted using a generalised linear model, with hatching or fledging success specified as a binary response: success [1] or failure [o]; models were fitted with a binomial error and a logit-link function. All statistical analyses were performed in SAS version 9.I (SAS Institute Inc. 2004).

\section{Results}

We obtained data on rats caught per trap night from 13 Mariana Crow nest sites for which we had accurate nest history data. Of these 13 nest sites, five failed to hatch their clutches, three hatched their clutches but did not fledge young, and five successfully fledged young.

The average number of rats caught per trap night across all nest sites showed very little variation among the three nights of trapping (night 1: 0.23; night 2: 0.23 night 3: 0.24), Within sites there was also relatively little variation around the index for each site, the average standard error of this index for each site was 0.046 (range: 0.01-0.14). However, the number of rats caught varied fivefold between nest sites, ranging from 0.09 to 0.46 rats per trap night, with a mean of 0.24 . We found no strong temporal trend in rats caught per trap night over the course of our trapping period (Figure 2).

In contrast to our prediction, we found a significant positive association between rats caught per trap night and both hatching success $\left(\chi^{2}{ }_{1}=5.40, P=0.02\right)$ and fledging success $\left(\chi^{2}{ }_{1}=12.86\right.$; $P=0.0003)$. Thus, crow pairs with nests located in areas with high rat abundance were more likely to both hatch their clutch and fledge young. The fitted relationship between rat abundance and probability of fledging success shows that nests in areas where our rat index was $>0.26$ had a $>50 \%$ chance of fledging young (Figure 3 ).

\section{Discussion}

In complete contrast to our predictions, we found a positive relationship between rats caught per trap night and breeding success. Despite the fact that our sample size was small and our data come from only one year, this result does suggest that predation by rats are unlikely to be a significant

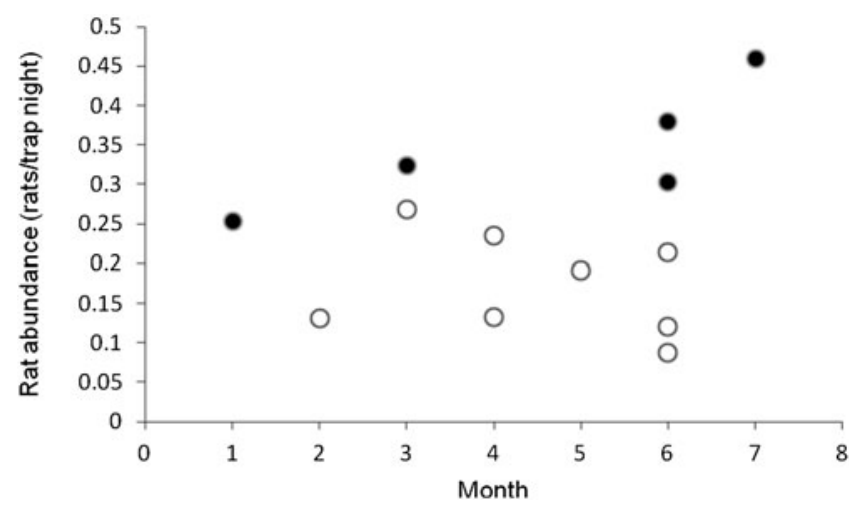

Figure 2. Relationship between rats caught per trap night and sampling month for successful nests (solid circles) and unsuccessful nests (open circles). No relationship is apparent between month of survey and rat abundance. Month $I=$ Dec 2002, Month $7=$ June 2003. 


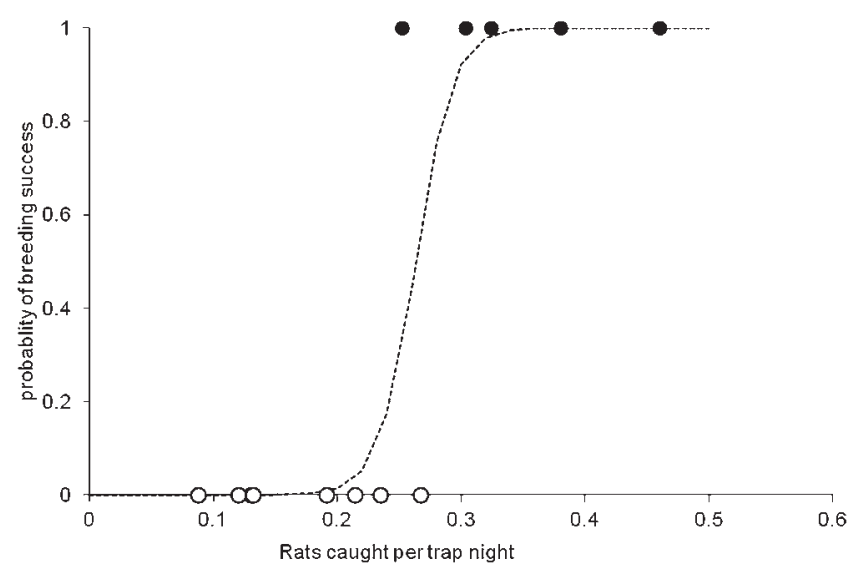

Figure 3. Modelled relationship between rats caught per trap night and probability of breeding success. Nests in areas with rat densities $>0.26$ rats per trap night, have a $>50 \%$ chance of breeding successfully.

cause of breeding failure for the Mariana Crow population on Rota, as has been previously proposed (Duckworth et al. 1997, USFWS 2005). However, because our study is correlational, it does not demonstrate unambiguously that rat control would not provide some benefit.

Whilst rats have been implicated in the decline of many island endemics, there is less evidence for a negative impact on terrestrial birds in the Mariana Islands, including Rota. Berry et al. (unpubl. data) filmed seven Mariana Crow nests, revealing three predation events, none of which involved rats: predators were Mariana Crows $(n=2)$ and Micronesian Starling Aplonis opaca $(n=1)$. Berry and Taisacan (2008), using video cameras, recorded two instances of nest predation on Rota White-eyes Zosterops rotensis, another endangered species endemic to Rota; one nest was preyed on by a Mariana Crow and the other by a rat, although the authors believed this may have occurred after abandonment of the nest due to the presence of the camera itself. Sachtleben (2005), using wax eggs and video cameras, identified to predation events on small passerine nests on the nearby island of Saipan. All predation events were attributed to avian predators (seven to Micronesian Starlings, two to Collared Kingfishers Halcyon chloris and one to an unidentified bird). These findings were also contrary to Sachtleben's predictions that rats would be the most important predator of nests. Furthermore, using automatic camera traps, Amar (2004) monitored predators at artificial nests containing chicken eggs set up within three crow territories. In one case, predation occurred after five days and was by a Mariana Crow. In the other two cases, the eggs remained after to days. However, the camera traps revealed several visits by rats, which had seemingly attempted, but failed to eat the eggs. Thus it appears that the chicken eggs were too tough or large (although these eggs were approximately 40\% longer and wider than Mariana Crow eggs) for rats to pierce. Similar findings are also described by Prieto et al. (2003), with R. rattus seemingly unable to predate intact chicken and Audouin's Gull Larus audouinii eggs. Whether this is true for Mariana Crow eggs is not known, but raises an interesting possibility.

It could be argued that because we only examined the relationship for those birds which bred, other pairs which did not breed may have had higher abundance of rats in their territories which somehow prevented them from breeding. However given that $90 \%$ of pairs examined in an earlier study attempted to breed (Morton et al. 1999) this seems unlikely. Additionally, another study (Amidon 2000) which collected data on rat abundance using an almost identical approach across four main areas of the crow's range on Rota, during a similar time of year (April 1999), found very similar densities $(0.21 \pm 0.04)$ to those of our study $(0.24 \pm 0.04)$, suggesting that our measures were representative of the landscape in which crows occur. 
In addition, because we used naive or apparent survival of crow nests, it could be argued that we may have missed other earlier failing nests, which could have been associated with high rat abundance. If so, this might negate or reverse the positive relationship we observed. To check these two possibilities, we carried out two additional analyses. Firstly, we simulated a number of failed nests (which were presumed to have been missed) with randomly generated high rat abundance (i.e. uniform distribution taken from the range of successful nests $0.26-0.46$ ); this analysis suggested that our significant positive relationship would only disappear if we had missed six early failing nests with high rat abundance, a situation which we view as unlikely. Secondly, using the limited data we had on total nest-day exposure (during the combined incubation and nestling period), we found that incorporating this exposure rate in the analysis (fitted as a denominator in the same binomial model) did little to alter the relationship we observed, although the positive relationship did become marginally non-significant $\left(\chi_{1}^{2}=3.02 ; P=0.08\right)$.

The cause of the significant positive relationship between rats caught per trap night and breeding success is unclear. However, this surprising result is potentially revealing for a species such as the Mariana Crow, for which there is limited ecological knowledge and illustrates the danger of using one-tailed statistical tests for such studies, which could have meant that such a positive association would be ignored (Rice and Gaines 1994). This relationship is unlikely to be causal, although a mechanism does exist (i.e. if rat young were an important item in the crow's diet although we never witnessed such predation, and rats are principally nocturnal and therefore have limited exposure to diurnal crows). One possible explanation is that Mariana Crows and rats have similar habitat preferences, such that habitat promoting high abundance of rats is also beneficial for Mariana Crow breeding success. Food resources are a potential mechanism for such a relationship, as rats and crows are both omnivores and their diets may comprise many shared food items, such as fruit and insects. If food availability was the cause of the relationship found, then it would be potentially important for the conservation of the species, since it may suggest that food is limiting the breeding success of the population. A recent analysis of some historical Mariana Crow nesting data on Rota provides some support for this explanation; successful nests differed from unsuccessful sites by being associated with plant species indicative of maturing, undisturbed, native limestone forest, a habitat which may provide more foraging opportunities for both rats and crows (Ha et al. 2011). It would be relatively undemanding to test this experimentally with a supplementary feeding experiment and explore whether additional food improves their breeding performance.

Alternatively, the positive relationship could be driven by a shared predator of rats and crows, such that in areas with high predator abundance, crows and rats would both suffer higher predation (Ritchie and Johnson 2009). However, why a predator's abundance would vary between areas is less clear, although there was some degree of spatial separation between successful and failed nests (Figure I), which might support this explanation. The predator involved would most likely be feral domestic cats Felis catus, which are present on Rota and can suppress rat numbers (Rayner et al. 2007) - this could be tested with little disturbance to crows, by radio tracking rats and examining the causes of mortality. Another predator on Rota, the monitor lizard Varanus indicus, is unlikely to suppress rat abundance (Uchida 1966). Amar et al. (2008) discussed the possibility of predation as the cause of the widespread decline of forest bird species on Rota and speculated that the predators involved would have to be too large to fit into the cavities of Micronesian starlings, which were the only species not to show significant declines between 1982 and 2004, and feral cats fulfil this criterion. Furthermore, a recent survival analysis of colour-ringed Mariana Crows revealed that over the last 20 years survival rates have declined, in particular those of first year birds have fallen dramatically (Ha et al. 2010). Increased predation could be an explanation for this decline and initial findings from radio-tracked fledglings have indicated that feral cats are important predators. Thus, there is some anecdotal support for this hypothesis and a cat removal study is currently underway on Rota to test this issue (R. Ha pers. comm.).

The results from this study emphasise the importance of gathering sufficient knowledge on a species's ecology prior to undertaking costly and logistically difficult experiments to ensure that 
such experiments test the most plausible cause of a decline. If this early stage of investigation within the declining population paradigm (Caughley 1994) is ignored, limited resources for conservation research may be misdirected. It could however, also be argued that the Mariana Crow is now so rare, that even if only a tiny fraction of nests fail due to rats, their control may still be warranted, but such a decision must ultimately be based on the resources available for conservation management.

\section{Acknowledgements}

We are grateful to Robert Ulloa, Linzi Seivwright and Isla Graham for help in the field and to Shelly Kramer, Tina de Cruz, and Laura Williams (CNMI-DFW) for logistical support. We are also grateful to many of the Guam - DAWR team, who showed us the locations of many of the pairs and trails; in particular we thank Tino Aguon, Blaine Dickie, Jeff Quitugua and Lyn Flores. We also thank Andrés Lira Noriega for preparing the map in Figure 1 and Fred Amidon and Gary Wiles for help with the manuscript.

\section{References}

Aguon, C. F., Campbell, E. W., III and Morton, J. M. (2002) The efficacy of electrical barriers used to protect Mariana Crow nests. Wildl. Soc. Bull. 30: 703-708.

Amar, A. (2004) Mariana Crow research project report, 2003-2004. Commonwealth of the Northern Mariana Islands: Division of Fish and Wildlife.

Amar, A., Amidon, F., Arroyo, B., Esselstyn, J. and Marshall, A. (2008) Population trends of the forest bird community on the Pacific island of Rota, Mariana Islands. Condor 110: $421-427$.

Amar, A. and Redpath, S. (2002) Determining the cause of the hen harrier decline on the Orkney Islands: an experimental test of two hypotheses. Anim. Conserv. 5: 21-28.

Amidon, F. A. (2000) Habitat relationships and life history of the Rota Bridled Whiteeye (Zosterops rotensis). M.Sc. thesis. Virginia Polytechnic Institute and State University, Blacksburg.

Atkinson, I. A. E. (1985) The spread of commensal species of Rattus to oceanic islands and their effects on island avifaunas, Pp. 3581 in Conservation of island birds. Paston, Norwich, UK: International Council for Bird Preservation. (ICBP Technical Publication 3).

Baker, R. H. (1946) A study of rodent populations on Guam, Mariana Islands. Ecol. Monogr. 16: 393-408.

Bell, B. D. (1978) The big South Cape Island rat irruption. Pp. 33-46 in P. R. Dingwall, I. A. E. Atkinson and Hay, C., eds. The ecology and control of rodents in New Zealand nature reserves. Wellington, NZ: Department of Land and Survey. (Information Series 4).

Berry, L. and Taisacan, E. (2008) Nest success and nest predation of the Endangered Rota White-eye (Zosterops rotensis). Wilson J. Ornithol. 120: 618-619.

BirdLife International (2003) BirdLife's online World Bird Database: the site for bird conservation. Version 2.o. Cambridge, UK: BirdLife International. Available: http:// www.birdlife.org (accessed 14/6/2004).

BirdLife International (2008) Corvus kubaryi. In: IUCN 2009. IUCN Red List of threatened species. Version 2009.1. <www.iucnredlist. org $>$. (accessed 05/10/2009).

Carleton, M. D. and Musser, G. G. (2005) Order Rodentia. Pp. 745-160o in D. E. Wilson and D. M. Reeder, eds. Mammal species of the world. Baltimore, USA: Johns Hopkins University Press.

Caughley, G. (1994) Directions in conservation biology. J. Anim. Ecol. 63: 215-244.

Duckworth, W. D., Beissinger, S. R., Derrickson, S. R., Fritts, T. H., Haig, S. M., James, F. C., Marzluff, J. M. and Rideout, B. A. (1997) The scientific bases for preservation of the Mariana Crow. Washington, DC: National Academy Press.

Falanruw, M. C., Cole, T. G. and Ambacher, A. H. (1989) Vegetation survey of Rota, Tinian, and Saipan, Commonwealth of the Northern Mariana Islands. Berkeley, California: Pacific 
Southwest Forest and Range Experiment Station.

Ha, J. C., Butler, A. and Ha, R. R. (2010) Reduction of first-year survival threatens the viability of the Mariana Crow Corvus kubaryi population on Rota, CNMI. Bird Conserv. Internatn. 20:335-342.

Ha, R. R., Morton, J. M., Ha, J. C., Berry, L. and Plentovich, S. (2011) Nest site selection and consequences for reproductive success of the endangered Mariana Crow Corvus kubaryi. Wilson J. Ornithol. 123: 236-242.

Igual, J. M., Forero, M. G., Gomez, T., Orueta, J. F. and Oro, D. (2006) Rat control and breeding performance in Cory's shearwater (Calonectris diomedea): effects of poisoning effort and habitat features. Anim. Conserv. 9: 59-65.

Jones, H. P., Tershy, B. R., Zavaleta, E. S., Croll, D. A., Keitt, B. S., Finkelstein, M. E. and Howald, G. R. (2007) Severity of the effects of invasive rats on seabirds: a global review. Conserv. Biol. 22: 16-26.

Kendrick, E., ed. (1997) Micronesia handbook. $4^{\text {th }}$ edition. Chico, CA: Moon Publications Inc.

Mayfield, H. (1975) Suggestions for calculating nest success. Wilson Bull. 87: 456-466.

Morton, J. M., Plentovich, S. and Sharp, T. (1999) USFWS final report: Reproduction and juvenile dispersal of Mariana Crows (Corvus kubaryi) on Rota 1996-1999. Honolulu: United States Fish \& Wildlife Service.

Nelson, L., Jr. and Clark, F. W. (1973) Correction for sprung traps in catch/effort calculations of trapping results. J. Mammal. 54: 295-298.

Newton, I. (1998) Population limitation in birds. London: Academic Press.

Ortiz-Catedral, L., Ismar, S. M. H., Baird, K., Brunton, D. H., and Hauber, M. E. (2009) Recolonization of Raoul Island by Kermadec red-crowned parakeets Cyanoramphus novaezelandiae cyanurus after eradication of invasive predators, Kermadec Islands archipelago, New Zealand. Conserv. Evid. 6: 26-30.

Parkes, J. P. Robley, A., Forsyth, D. M. and Choquenot, D. (2006) Adaptive management experiments in New Zealand and Australia. Wildl. Soc. Bull. 34: 229-236.
Plentovich, S., Morton, J., Cramp, R., Bart, J., Lush, M. and Johnson, M. (2005) Population trends of the Mariana Crow Corvus kubaryi on Rota, Commonwealth of the Northern Mariana Islands. Bird. Conserv. Internatn. 15: 211-224.

Prieto, J., Lez-Soli, J. G., Rutz, X. and Jover, L. (2003) Can rats prey on gull eggs? An experimental approach. Biodiv. Conserv. 12: 2477-2486.

Rayner, M. J., Hauber, M. E., Imber, M. J., Stamp, R. K. and Clout, M. N. (2007) Spatial heterogeneity of mesopredator release within an oceanic island system. Proc. Natl Acad. Sci. USA 104: 20862-20865.

Rice, W. R. and Gaines, S. D. (1994) 'Heads I win, tails you lose': testing directional alternative hypotheses in ecological and evolutionary research. Trends Ecol. and Evol. 9: 235-237.

Ritchie, E. G. and Johnson, C. N. (2009) Predator interactions, mesopredator release and biodiversity conservation. Ecol. Letters 12: 982-998.

Robins, J. H., Hingston, M., Matisoo-Smith, E. and Ross, H. A. (2007) Identifying Rattus species using mitochondrial DNA. Mol. Ecol. Notes 7: 717-729.

SAS Institute Inc. (2004) SAS/STAT 9.1 user's guide. Cary, NC: SAS Institute Inc.

Sachtleben, T. (2005) Predation and nest success of forest birds in native and nonnative habitat on Saipan, Mariana Islands. MSc Thesis, Colorado State Univeristy, Fort Collins, Colorado.

Thibault, J. C., Martin, J., L., Penloup, A. and Meyer, J. Y. (2002) Understanding the decline and extinction of monarchs (Aves) in Polynesian Islands, Biol. Conserv. 108: 161-174.

Towns, D. R., Atkinson, I. A. E. and Daugherty, C. H. (2006) Have the harmful effects of introduced rats on islands been exaggerated? Biol. Invasions 8: 863-891.

Uchida, T. A (1966) Observations on the monitor lizard, Varanus indicus (Daudin), as a ratcontrol agent on Ifaluk, Western Caroline Islands. Bull. World Health Organ. 35: 976-980.

USFWS (2005) Draft revised recovery plan for the Aga or Mariana Crow Corvus kubaryi. Portland, Oregon: United States Fish and Wildlife Service. 
Wiewel, A. S., Adams, Yackel, A. A. and Rodda, G. H. (2009) Distribution, density, and biomass of introduced small mammals in the Southern Mariana Islands. Pacific Sci. 2: 205-222.
Wiles, G. J., Bart, J., Beck, R. E., Jr, and Aguon, C. F. (2003) Impacts of the brown tree snake: Patterns of decline and species persistence in Guam's avifauna. Conserv. Biol. 17: $1350-1360$.

\section{ARJUN AMAR*}

Percy FitzPatrick Institute of African Ornithology, DST/NRF Centre of Excellence, University of Cape Town, Private Bag X3, Rondebosch, 7701, South Africa.

\section{JACOB A. ESSELSTYN}

McMaster University, Biology Department, Life Sciences Building Room 328, Hamilton, Ontario L8S4K1, Canada.

*Author for correspondence: arjun.amar@uct.ac.za

Received 19 September 2012; revision accepted 23 January 2013; Published online 28 March 2013 